\title{
THE WAYS FOR DEVELOPMENT OF ENVIRONMENTALLY SAFE SOLID COMPOSITE PROPELLANTS
}

\section{B. Lempert, G. B. Manelis, and G. N. Nechiporenko}

The paper considers a wide set of issues concerning the creation of high energetic solid composite propellants causing the minimal polluting effect on the environment. Thereby, the level of toxicity of products of different compositions is discussed and propellants with perchlorates oxidizers are compared with propellants with halogen free oxidizers (mainly, ammonium dinitramide, HMX, CL-20). The main methods for creating compositions having a required performance and the highest energetic characteristics are also under discussion. The dependences of the specific impulse on the mode of formulation arrangement and on the compounds' properties (i.e., formation enthalpy, density, element content) are demonstrated. The main principles for the maximal use of energetic potential of chemical substances are under consideration. These are the proper selection of the binder type which would be optimal for the given mixture of oxidizer with fuel (or energetic) component and the opportunity of using metals and their hydrides (mainly, aluminum hydride $(\mathrm{AH})$ ). Main obstacles in using different kinds of compositions, as well as advantages of specific propellants are under consideration as well. A special attention is paid to the interrelationship between the energetic parameter and other performances (thermal stability, combustion law, sensitivity, and compatibility).

\section{INTRODUCTION}

Low environmental impact of combustion products often becomes a prime condition for rocket propellants. What products constitute the environmental problem? Naturally, both the amount of a certain component released and its relative toxicity should be taken into account. At high toxicity, even trace concentrations of supertoxicants (e.g., dioxins) in the combustion products may become a major problem, whereas less toxic $\mathrm{HF}, \mathrm{HCl}$, and even $\mathrm{CO}$ become dangerous only in large amounts. Since a rocket launch is occasional, its environmental impact should be assessed differently from that produced by the exhaust of the same products in continuous industrial processes. The conditions in which a 
solid propellant is used are also important. For example, the use of beryllium is absolutely unacceptable in the first stages of rocket launchers, while it can be used in the outer space.

\section{MAJOR TOXIC COMBUSTION PRODUCTS OF SOLID COMPOSITE PROPELLANTS RELEASED INTO ENVIRONMENT}

Toxic substances cannot be avoided completely. Even CO and NO are toxic and always form (especially, CO) at equilibrium concentrations at high-temperature combustion of CHNO systems. For example, combustion of a simple formulation of $13 \%$ hydrocarbon binder $(\mathrm{HB})+20 \% \mathrm{Al}+\mathrm{ADN}$ results in the $\mathrm{CO}$ concentration at the nozzle exit (at $2200 \mathrm{~K}$ ) of $9.6 \mathrm{~mol} / \mathrm{kg}=270 \mathrm{~g} / \mathrm{kg}$. Since the limiting allowable concentration (LAC) for $\mathrm{CO}$ is $3 \mathrm{mg} / \mathrm{m}^{3}$ (Russian standard), $2.7 \cdot 10^{9} \mathrm{mg}$ CO released in the course of combustion of a 10-ton propellant charge must be diluted in $1 \mathrm{~km}^{3}$ to bring it to the LAC.

Similar pattern is observed for $14 \% \mathrm{HB}+20 \% \mathrm{Al}+$ ammonium nitrate $(\mathrm{AN})$ (the formulation temperature at the nozzle exit $T_{a}$ is $1800 \mathrm{~K}$ ). It is virtually impossible to fight $\mathrm{CO}$, as the shift in oxygen balance and elimination of $\mathrm{Al}$ (this will reduce $\mathrm{CO}$ concentration as well) result in the dramatic drop of pocket performance. In addition, one should take into account that after leaving the nozzle, the hot $(\sim 2000 \mathrm{~K})$ gaseous products containing $\mathrm{CO}$ mix with air and a substantial part of $\mathrm{CO}$ is oxidized to $\mathrm{CO}_{2}$. For this reasoning, this paper does not deal with $\mathrm{CO}$ as an environmentally harmful substance.

Similar consideration applies to nitrogen oxides. Those are always present in the rocket motor exhaust in the concentrations not lower than the equilibrium one. In fact, NO concentrations are even higher, since NO, the second (after molecular nitrogen) major nitrogen-containing product of combustion, is quenched due to gas cooling during expansion. The calculated equilibrium NO concentration at the nozzle exit at $\sim 2100 \mathrm{~K}$ comprises $10^{-8}-10^{-7} \mathrm{~mol} / \mathrm{kg}$. Thus, the concentration of NO is $8-9$ decimal orders lower than that of $\mathrm{CO}$, so even with the account of LAC, two orders of magnitude lower than that of $\mathrm{CO}$, atmospheric pollution with $\mathrm{NO}$ can be considered as minor.

During '50s-'70s of the XX century, an interest arouse to the formulations containing beryllium and its hydride. As a matter of fact, substitution of aluminum by beryllium brings a substantial increase in the specific impulse. Table 1 presents the calculation data on energy properties of the formulations based on $\mathrm{HB}$, oxidizer, and metal. One can see that substitution of aluminum by beryllium increases the specific impulse by approximately 20 units. Naturally, the largest gain is achieved for the formulations with AN which need the additional energy to the utmost. It will be seen below that a ratio of components in each 
Table 1 Comparison of beryllium- and aluminum-containing formulations: $I_{\mathrm{sp}}$ is the specific impulse at $P_{c}: P_{a}=40: 1 ; P_{c}$ and $P_{a}$ are the pressures (in atm) in combustion chamber and at the nozzle exit, respectively; $\rho$ is the density; and $E 3$ - see subsection 4.1

\begin{tabular}{llcc}
\hline \multicolumn{1}{c}{ Formulation } & $I_{\mathrm{sp}}, \mathrm{s}$ & $\rho, \mathrm{g} / \mathrm{cm}^{3}$ & $E_{3}, \mathrm{~g}, \mathrm{~cm}^{3}, \mathrm{~s}$ \\
\hline $12 \% \mathrm{HB}+20 \% \mathrm{Al}+\mathrm{AN}$ & 244.4 & 1.67 & 270.8 \\
$14 \% \mathrm{HB}+12 \% \mathrm{Be}+\mathrm{AN}$ & 268.7 & 1.52 & 292.2 \\
$12 \% \mathrm{HB}+20 \% \mathrm{Al}+\mathrm{ADN}$ & 261.7 & 1.73 & 292.0 \\
$14 \% \mathrm{HB}+12 \% \mathrm{Be}+\mathrm{ADN}$ & 281.8 & 1.60 & 309.6 \\
$10 \% \mathrm{HB}+22 \% \mathrm{Al}+\mathrm{AP}$ & 251 & 1.85 & 283.9 \\
$12 \% \mathrm{HB}+12 \% \mathrm{Be}+\mathrm{AP}$ & 265.5 & 1.705 & 295.4 \\
\hline
\end{tabular}

composition described in this paper has been chosen based on the following principles:

(a) binder content is not lower than $18-20 \%$ (vol.), otherwise, it would be too hard or even impossible to create the composition; and

(b) maximal metal content is not higher than the value when at which the mass percentage of its oxide in the combustion products is higher than $36 \%-38 \%$, otherwise, a slagging occurs in the course of combustion process.

Finally, the composition meeting conditions (a) and (b) with the highest $I_{\mathrm{sp}}$ value or highest ballistic efficiency has been selected.

Nevertheless, the excessively high toxicity of beryllium and its derivatives (LAC in air is $0.001 \mathrm{mg} / \mathrm{m}^{3}$, i.e., combustion products of each ton of Becontaining propellant contaminate $100 \mathrm{~km}^{3}$ of air) prohibits the use of such fuels in the first stages of rocket launchers. Of course, their use in the upper atmosphere and especially in the outer space is well justified, especially, as they are more efficient for the higher stages. However, even test ground firings of such formulations can result in dramatic beryllium pollution.

For combustion of perchlorate-based formulations, hydrogen chloride is a massive product (up to $20-25 \%$ (wt.)). It is an ozone depleting gas. In addition, upon launch or disposal of rockets on the Earth surface, vegetation suffers on a vast territory $\left(\mathrm{HCl} \mathrm{LAC} \mathrm{is} 5 \mathrm{mg} / \mathrm{m}^{3}\right)$. Hydrogen chloride precipitates mainly as hydrochloric acid directly over the launch site covering the area of 1-2 ha. However, its fallout was detected at a distance up to $7-8 \mathrm{~km}$, and its concentration in nearby localities sometimes exceeds the LAC by a factor of 20 .

The other dangerous combustion products of chlorine-containing formulations are excessively toxic dioxins, the compounds of general formula: 
<smiles></smiles>

where $\mathrm{R}=\mathrm{H}$ or $\mathrm{Cl}$, with 1 to 8 chlorine atoms. As their LAC in air is $5 \cdot 10^{-11} \mathrm{mg} / \mathrm{m}^{3}$, a very small amount of dioxins may create a serious problem. Particularly, strong release of dioxins occurs at thrust cutoff, i.e., when the motor completes its operation. When the concentration of hydrogen becomes lower than that of chlorine, the equilibrium concentrations of dioxins increase by many decimal orders and constitute major chlorine-containing products.

Thus, the major objective of this paper is to describe a possibility to substantially reduce the environmental danger of solid propellants through the use of formulations based on ammonium perchlorate (AP) and to propose the most promising formulations containing neither beryllium, nor fluorine or chlorine.

\section{POSSIBILITIES OF DEVELOPING PROPELLANTS BASED ON AMMONIUM PERCHLORATE WITH SUBSTANTIALLY IMPROVED ENVIRONMENTAL PERFORMANCE}

At present, AP is the cheapest and most available oxidizer among highly potential ones (those based on cheap AN have low density and specific impulse, those based on ammonium dinitramide (ADN) provide high $I_{\mathrm{sp}}$ but possess lower density and are substantially more expensive), but whenever a formulation incorporates only $\mathrm{C}, \mathrm{H}, \mathrm{O}, \mathrm{N}, \mathrm{Al}$, and $\mathrm{Cl}$, the chlorine in the combustion products appears in the form of gaseous $\mathrm{HCl}$. Chlorine can be neutralized to safe solid products only with alkaline metals in quantities no less than equivalent to chlorine. This is possible with substitution of AP by lithium, sodium, or potassium perchlorates [1], but lithium perchlorate is excessively hygroscopic and the formulations based on potassium perchlorate have lower energy due to high atomic mass of potassium. There is a possibility to prepare a formulation with equimolar mixed oxidizer $\mathrm{AP}: \mathrm{NaNO}_{3}(\mathrm{SN})$.

The data of Table 2 show that at the nozzle exit at about $3000 \mathrm{~K}$, the formulations based on the mixed AP : SN oxidizer yield $\mathrm{HCl}$ concentration 5 times lower than the formulations based on AP; with further cooling, this concentration drops due to the reaction of $\mathrm{HCl}$ with sodium species (primarily, sodium vapors) and at 1200-1300 K, the concentration of $\mathrm{HCl}$ becomes negligible.

How does introduction of sodium affect equilibrium concentrations of dioxins? The calculations were performed for equilibrium concentrations of dioxins 
Table 2 Some formulations based on AP : SN oxidizer. $T_{c}$ and $T_{a}$ are the temperatures in combustion chamber and nozzle exit, respectively

\begin{tabular}{|c|c|c|c|c|c|c|c|}
\hline System & $\begin{array}{c}I_{\mathrm{sp}}, \\
\mathrm{s}\end{array}$ & $\begin{array}{c}\rho, \\
\mathrm{g} / \mathrm{cm}^{3}\end{array}$ & $\begin{array}{c}T_{c} \\
\mathrm{~K}\end{array}$ & $\begin{array}{c}T_{a}, \\
\mathrm{~K}\end{array}$ & $\begin{array}{c}\mathrm{HCl}+\mathrm{Cl}_{2} \\
\mathrm{~mol} / \mathrm{kg}\end{array}$ & $\begin{array}{c}\mathrm{CO}, \\
\mathrm{mol} / \mathrm{kg}\end{array}$ & $\begin{array}{c}\mathrm{H}_{2}, \\
\mathrm{~mol} / \mathrm{kg}\end{array}$ \\
\hline $\mathrm{AP}+\mathrm{HB}+\mathrm{Al}$ & 251 & 1.84 & 3610 & 2520 & 6 & 7 & 10 \\
\hline $\mathrm{AP}+$ & 240 & 1.76 & 3000 & 1900 & 7.8 & 0.8 & 0.5 \\
\hline $\mathrm{NaClO}_{4}+\mathrm{HB}$ & 211 & 2.0 & 3080 & 2030 & 0.25 & 2 & 0.5 \\
\hline $\mathrm{NaClO}_{4}+\mathrm{HB}+\mathrm{Al}$ & 225 & 2.05 & 3650 & 2610 & 1.1 & 10 & 7 \\
\hline $\mathrm{AP}: \mathrm{NaNO}_{3}+\mathrm{HB}+\mathrm{Al}$ & 230 & 1,96 & 3665 & 2990 & 1.5 & 4.7 & 4.4 \\
\hline $\mathrm{AP}: \mathrm{NaNO}_{3}+20 \% \mathrm{HMX}+\mathrm{HB}+\mathrm{A}$ & 234 & 1.936 & 3630 & 2610 & 0.9 & 7.1 & 10.3 \\
\hline
\end{tabular}

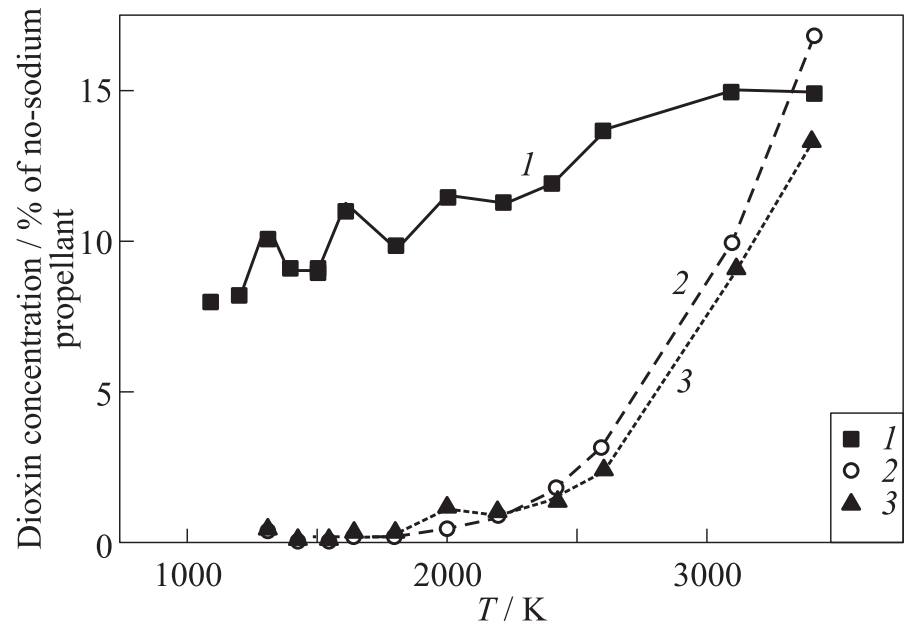

Figure 1 The equilibrium concentration of dioxins in combustion products for the formulations based on $\mathrm{AP}+\mathrm{SN}$ vs. temperature: $1-\mathrm{AP}: \mathrm{SN}=1: 0.9 ; 2-1: 1$; and $3-\mathrm{AP}: \mathrm{SN}=1: 1.1$

in the combustion products of a standard formulation $\mathrm{Al}+\mathrm{AP}+\mathrm{HB}$. The thermodynamic calculations showed that with the introduction of $\mathrm{SN}$, the content of dioxins drops dramatically and depending on temperature it comprises from $0.5 \%$ to $15 \%$ of that attained without sodium.

Figure 1 shows the examples of the formulations based on AP : SN, with the molar ratio $\mathrm{AP} / \mathrm{SN}=0.9,1.0$, and 1.1. In the temperature range below $2500 \mathrm{~K}$, the yield of dioxins drops as the sodium to chlorine molar ratio increases to 1 . Further increase of SN molar fraction in the oxidizer does not lead to reduction in dioxin concentration compared to equimolar AP : SN. 
Thus, the formulations based on AP : SN mixture provide a possibility of reducing substantially the release of both hydrogen chloride and dioxins to the environment.

\section{FORMULATIONS BASED ON HALIDE-FREE OXIDIZERS}

In the course of development of propellant formulations, not only energy parameters and environmental performance discussed afore must be taken into account. The issues to be addressed also include thermal stability, compatibility of constituents, sensitivity to impact and friction, required combustion law, and others including the cost. Each of the halides-free oxidizers discussed below has its own merits and drawbacks, which must be taken into account when developing a composition for a particular task (conditions of storage, safety margin, strength of combustion chamber casing, etc.).

The list of chlorine-free oxidizers presented in Table 3 is exhaustive for practical applications. Possible extensions of this list will be discussed further.

Ammonium-nitrate-based formulations are considered in a complementary paper. Here, it is worth mentioning that $\mathrm{AN}$ is the oxidizer with the lowest energy potential due to its low $\Delta H_{f}^{0}$ value and low density; nevertheless, a proper choice of binder in the presence of metals can narrow the loss for AP-based formulations.

Starting to discuss the solid propellants based on other oxidizers listed in Table 3, note that it is mainly the oxidizer (depending on its chemical formulation and $\Delta H_{f}^{0}$ ) that predetermines the energy potential of solid propellant. However, in order to make a formulation where the energy potential of an oxidizer is materialized to its best, one must carefully select other components, namely, energetic component (metal, hydride) and binder according to the rule of thumb: the binder should compensate in its chemical composition the disadvantages of other components.

For example, if oxidizer is rich in oxygen and the formulation contains little or no metal, the binder should be rich in hydrogen; if the formulation contains hydride or an oxygen-deficient oxidizer (e.g., HMX), the binder must take some oxidizer functions (say, contain functional groups like $\mathrm{NO}_{2}, \mathrm{NO}_{3}$ ), etc.

In this paper, the formulations with different types of binder are considered, namely:

$$
\begin{aligned}
& \mathrm{HB}, \Delta H_{f}=-390 \mathrm{~kJ} / \mathrm{kg}, \rho=0.91 \mathrm{~g} / \mathrm{cm}^{3}, \text { hydrogen content } \sim 12 \% \\
& \text { poly(methylvinyltetrazol) } \quad(\mathrm{PMVT})-\left(\mathrm{C}_{4} \mathrm{~N}_{4} \mathrm{H}_{6}\right)_{n}, \quad \text { a high-enthalpy polymer } \\
& \quad \text { with high nitrogen content }(\sim 46 \%), \Delta H_{f}=+1255 \mathrm{~kJ} / \mathrm{kg}, \rho=1.28 \mathrm{~g} / \mathrm{cm}^{3} ;
\end{aligned}
$$


Table 3 Major halide-free oxidizers

\begin{tabular}{|c|c|}
\hline Oxid & Drawbacks \\
\hline $\begin{array}{c}\text { Ammonium } \mathrm{n} \\
\mathrm{NH}_{4} \mathrm{NO}_{3} \\
\mathrm{AN}\end{array}$ & $\begin{array}{l}\text { Availability, low cost, Low energy potential because } \\
\text { high oxygen content, of the low enthalpy of forma- } \\
\text { sufficient thermal sta- tion }\left(\Delta H_{f}^{0}=-4514 \mathrm{~kJ} / \mathrm{kg}\right) \text {, } \\
\text { bility, good compati- low density }\left(1.725 \mathrm{~g} / \mathrm{cm}^{3}\right) \text {, } \\
\text { bility with other com- low combustion rate, phase } \\
\text { ponents, low sensitivity transitions in the operational } \\
\text { temperature range }\end{array}$ \\
\hline $\begin{array}{rr}\oplus & \odot \\
\mathrm{NH}_{4} & \mathrm{~N} \\
& \mathrm{ADN}\end{array}$ & $\begin{array}{l}\text { High energetic poten- Limited supply, high cost } \\
\text { tial, satisfactory com- } \\
\text { bustion law, satisfac- } \\
\text { tory thermal stability, } \\
\text { compatibility, and sen- } \\
\text { sitivity }\end{array}$ \\
\hline $\begin{array}{r}\mathrm{O}_{2} \mathrm{~N} \\
\mathrm{HI}\end{array}$ & $\begin{array}{ll}\text { Availability, moderate } & \text { Poor combustion law (large } \\
\text { cost, high thermal sta- } & \text { exponent } \nu \text { in the pressure } \\
\text { bility, satisfactory com- } & \text { dependence of combustion } \\
\text { patibility } & \left.\text { rate } W=A P^{\nu}\right) \text {, relatively } \\
& \text { high sensitivity, susceptibility } \\
& \text { to deflagration-to-detonation } \\
& \text { transition }\end{array}$ \\
\hline${ }_{2} \mathrm{NN}$ & $\begin{array}{l}\text { High density, satisfac- Same as HMX }+ \text { high cost } \\
\text { tory thermal stability } \\
\text { and compatibility }\end{array}$ \\
\hline $\begin{array}{c}\text { Hydrazonium nitroformate, } \\
\mathrm{N}_{2} \mathrm{H}_{5}^{+}-\mathrm{C}\left(\mathrm{NO}_{2}\right)_{3} \\
\mathrm{HNF}\end{array}$ & $\begin{array}{ll}\text { otential } & \text { High sensitivity, poor com- } \\
& \text { patibility, lack of mass pro- } \\
& \text { duction }\end{array}$ \\
\hline
\end{tabular}

active binder (AB), a model binder analogous to practical ones, $20 \%$ PMVT, extended with a mixture of trinitroglycerol with 2,4-dinitro-2,4-diazopentane; its gross formula is close to $\mathrm{C}_{19} \mathrm{H}_{34.5} \mathrm{~N}_{19} \mathrm{O}_{29.5}$; $\Delta H_{f}=-757 \mathrm{~kJ} / \mathrm{kg}, \rho=1.49 \mathrm{~g} / \mathrm{cm}^{3}$, oxygen content $\sim 47 \%$; and

poly(vinylmethoxydiazen-N-oxide) (PVMDO) $\left(\mathrm{C}_{3} \mathrm{H}_{6} \mathrm{~N}_{2} \mathrm{O}_{2}\right)_{n}, \Delta H_{f}=0 \mathrm{~kJ} / \mathrm{kg}$, $\rho=1.31 \mathrm{~g} / \mathrm{cm}^{3}$, a model binder rich in hydrogen $(\sim 6 \%)$ and oxygen $(\sim 31 \%)$. 


\subsection{Formulations Based on Dinitramide Salts}

Ammonium dinitramide is a relatively new oxidizer first synthesized in Russia in 1972. During 10-15 years, methods of synthesis, purification, and stabilization were developed, industrial production was implemented, and even practical motors based on ADN-propellants were manufactured [2]. Ammonium dinitramide has a favorable chemical composition and sufficiently high $\Delta H_{f}^{0}$ value; hence, the ADN-based formulations have the highest $I_{\mathrm{sp}}$ among those based on other oxidizers (except HNF) listed in Table 3. However, a low density of ADN makes it better suited for the formulations used in the higher stages. On the lower stages, it loses a bit to AP.

Table 4 presents the calculated properties of the formulations based on ammonium, hydrazonium, and guanidinium salts of dinitramide. Since different oxidizers possess different density and the density of propellant $(\rho)$ substantially affects the ballistics, the formulations were compared not only by $I_{\mathrm{sp}}$ but also by the so-called ballistic efficiency $\left(E_{i}\right)$ of the $i$ th stage of a rocket launcher. The ballistic efficiency [3] of the $i \operatorname{th}$ stage $\left(E_{i}\right)$ is defined as $E_{1}=I_{\mathrm{sp}} \rho^{0.6}, E_{2}=I_{\mathrm{sp}} \rho^{0.4}$, and $E_{3}=I_{\mathrm{sp}} \rho^{0.2}$. These exponent values $(0.2,0.4$, and 0.6$)$ correspond to threestage rocket launchers with optimized stage masses and tank volumes of every stage. Using these equations, one can affirm that, e.g., if there are two different propellants (the first one possessing $I_{\mathrm{sp} 1}$ and $\rho_{1}$ while the second one possessing $I_{\mathrm{sp} 2}$ and $\rho_{2}$ ) the usage of the first propellant in the first stage would provide higher speed growth than the usage of the second propellant (the propellants

Table 4 Energy potential of formulations based on dinitramide salts

\begin{tabular}{|c|c|c|c|c|c|c|c|}
\hline Oxidizer & $\begin{array}{c}\text { Binder } \\
\text { type }\end{array}$ & $\begin{array}{l}\text { Binder, } \\
\% \text { (wt.) }\end{array}$ & $\begin{array}{c}\text { Energetic } \\
\text { compound, } \\
\%\end{array}$ & $\underset{\%}{\operatorname{HMX}}$ & $\begin{array}{c}I_{\mathrm{sp}} \\
\mathrm{s}\end{array}$ & $\begin{array}{c}\rho, \\
\mathrm{g} / \mathrm{cm}^{3}\end{array}$ & $\begin{array}{c}E_{1} \quad E_{2} \quad E_{3} \\
\mathrm{~g}, \mathrm{~cm}^{3}, \mathrm{~s}\end{array}$ \\
\hline \multirow{8}{*}{$\mathrm{NH}_{4} \mathrm{~N}\left(\mathrm{NO}_{2}\right)_{2}$} & HB & 12 & 0 & 0 & 246.9 & 1.625 & $\begin{array}{lll}330.4 & 299.8272 .1\end{array}$ \\
\hline & \multirow{2}{*}{ PMVT } & 18 & $14 \mathrm{Al}$ & 0 & 258.0 & 1.767 & $\begin{array}{llll}363.0 & 324.0 & 289.1\end{array}$ \\
\hline & & 18 & $20 \mathrm{Al}$ & 0 & 259.5 & 1.802 & $369.5 \quad 328.4291 .9$ \\
\hline & \multirow[b]{2}{*}{ HB } & 12 & $16 \mathrm{Al}$ & 0 & 260.7 & 1.704 & $\begin{array}{lll}358.9 & 322.6 & 290.0\end{array}$ \\
\hline & & 12 & $20 \mathrm{Al}$ & 0 & 261.7 & 1.725 & $\begin{array}{lll}363.0 & 325.5 & 291.9\end{array}$ \\
\hline & \multirow{3}{*}{$\mathrm{AB}$} & 18 & $16 \mathrm{Al}$ & 20 & 258.3 & 1.833 & $\begin{array}{llll}371.6 & 329.1291 .6\end{array}$ \\
\hline & & 18 & $22 \mathrm{Al}$ & 20 & 259.6 & 1.870 & $\begin{array}{lll}377.9 & 333.5 & 294.2\end{array}$ \\
\hline & & 18 & $11 \mathrm{~B}$ & 0 & 256.4 & 1.781 & $\begin{array}{lll}362.5 & 323.0 & 287.8\end{array}$ \\
\hline \multirow[t]{3}{*}{$\mathrm{N}_{2} \mathrm{H}_{5} \mathrm{~N}\left(\mathrm{NO}_{2}\right)_{2}$} & HB & 12 & - & 0 & 251.2 & 1.625 & $\begin{array}{llll}336.1 & 305.0 & 276.8\end{array}$ \\
\hline & \multirow{2}{*}{$\mathrm{AB}$} & 20 & - & 0 & 251.6 & 1.742 & $\begin{array}{llll}351.0 & 314.1281 .1\end{array}$ \\
\hline & & 20 & $10 \mathrm{~B}$ & 0 & 262.3 & 1.774 & $\begin{array}{lll}370.0 & 329.9 & 294.2\end{array}$ \\
\hline $\mathrm{C}\left(\mathrm{NH}_{2}\right)_{3} \mathrm{~N}\left(\mathrm{NO}_{2}\right)_{2}$ & $\mathrm{AB}$ & 18 & $20 \mathrm{Al}$ & 0 & 254.2 & 1.824 & $\begin{array}{llll}364.6 & 323.3 & 286.7\end{array}$ \\
\hline
\end{tabular}


used in the 2nd and 3rd stages being equal) if $I_{\mathrm{sp} 1} \rho_{1}^{0.6}>I_{\mathrm{sp} 2} \rho_{2}^{0.6}$. Naturally, the exponents for density depend on the volume-to-mass ratio for each stage and can differ substantially.

To date, ADN is the most efficient oxidizer for solid propellants (especially, for upper stages) among the industrially produced ones. The formulations with AB and boron can provide the highest ballistic efficiency, as boron-based propellants have no condensed combustion products and hence, experience no two-phase losses of specific impulse (this losses are typical of Al-based formulations).

\subsection{Formulations Based on Organic Oxidizers}

The available choice of candidate inorganic oxidizers suitable for propellants is limited indeed. Those include onium nitrates, perchlorate, and dinitramide salts. Salts of other acids are either less energetic or unstable (when the acid is weak). The chemistry of organic oxidizers provides a wider choice.

\subsection{Formulations Based on HMX}

RDX and HMX are the well developed commercially produced explosives. HMX takes over RDX in energy, as with the same element content and approximately equal $\Delta H_{f}^{0}(314-334 \mathrm{~kJ} / \mathrm{kg}) \mathrm{HMX}$ has a substantially higher density (1.91 vs. $\left.1.80 \mathrm{~g} / \mathrm{cm}^{3}\right)$. Therefore, this subsection deals only with HMX. HMX is not used as an individual oxidizer in solid propellants. Its advantage of high $\Delta H_{f}^{0}$ is combined with a disadvantage - it is not sufficiently rich in oxygen. For this reason, it should be used only with a highly active binder (Table 5).

Another drawback of HMX (typical also of other CHNO oxidizers) is that the formulations based on it have a high value of exponent $\nu$ in the combustion law $W=A P^{\nu}$. Therefore, systems with high HMX content are dangerous for

Table 5 Energy potential of formulations based on HMX and AB

\begin{tabular}{crcccccccc}
\hline $\begin{array}{c}\text { Binder, } \\
\% \text { (wt.) }\end{array}$ & $\begin{array}{c}\mathrm{Al}, \\
\%\end{array}$ & $\begin{array}{c}\text { Additional } \\
\text { compound }\end{array}$ & $\begin{array}{c}I_{\mathrm{sp}}, \\
\mathrm{s}\end{array}$ & $\begin{array}{c}\rho, \\
\mathrm{g} / \mathrm{cm}^{3}\end{array}$ & $\begin{array}{c}T_{c}, \\
\mathrm{~K}\end{array}$ & $\begin{array}{c}T_{a}, \\
\mathrm{~K}\end{array}$ & $\begin{array}{c}E_{1} \\
\mathrm{~g}, \mathrm{~cm}^{3}, \mathrm{~s}\end{array}$ & $E_{3}$ \\
\hline 10 & 0 & 0 & 252.4 & 1.85 & 3210 & 1690 & 365.1 & 322.8 & 285.4 \\
16 & 0 & 0 & 251.3 & 1.82 & 3180 & 1660 & 359.9 & 319.3 & 283.3 \\
16 & 16 & 0 & 262.0 & 1.91 & 3670 & 2360 & 386.3 & 339.4 & 298.2 \\
16 & 16 & $6 \% \mathrm{AP}$ & 261.2 & 1.91 & 3713 & 2425 & 385.0 & 338.3 & 297.3 \\
16 & 12 & 0 & 261.0 & 1.88 & 3590 & 2300 & 381.2 & 336.0 & 296.1 \\
16 & 0 & $6 \% \mathrm{~B}$ & 250.7 & 1.84 & 3120 & 1820 & 361.4 & 319.9 & 283.2 \\
\hline
\end{tabular}


possibility of deflagration-to-detonation transition or failure of motor casing due to uncontrolled pressure rise in the combustion chamber. At the same time, use of up to $25 \%$ HMX in combination with another oxidizer is relatively safe and for certain systems, this secures improved energetic parameters (e.g., when AP is the major oxidizer). But this is not a common rule; ADN does not require HMX. In order to secure a favorable combustion law for the formulations based on HMX and an AB, one usually introduces a small amount of AP (5\%-10\%) even at the expense of a small drop of energetic parameters.

\subsection{Formulations Based on High-Enthalpy Organic Oxidizers}

Recently, a number of publications has been devoted to synthesis and investigations of properties of other organic compounds with high oxygen content and relatively high $\Delta H_{f}^{0}$. Those are mainly the compounds based on high-enthalpy structures: strained carbon cycles (cubane), acetylene derivatives, nitrogen-containing heterocycles (aziridines, furazanes, furoxanes, triazoles, tetrazoles, etc.).

Recently, CL-20 has been studied extensively [4]; this is a high-density highenthalpy compound ( $\Delta H_{f}^{0} \sim 840 \mathrm{~kJ} / \mathrm{kg}, \rho=2.04 \mathrm{~g} / \mathrm{cm}^{3}$, see Table 3). However, authors' analysis has shown that despite these advantages over HMX, CL-20 is more efficient than HMX only in first stages of multistage rocket launchers (exclusively due to higher density). Because of a lower hydrogen fraction (almost twofold as compared with HMX), CL-20 is virtually equivalent to HMX in the second stage and less effective in the third stage.

In early $1980 \mathrm{~s}$, octanitrocubane $\left(\Delta H_{f}^{0}=+250 \mathrm{kcal} / \mathrm{kg}, \rho \approx 1.98 \mathrm{~g} / \mathrm{cm}^{3}\right)$ arose much hope. Much effort was devoted to synthesis of this oxidizer. However, the attainable energy performance of octanitrocubane (Table 6) may not payoff the bitter problems encountered in the synthesis. Not so high ballistic efficiency of octanitrocubane stems from the absence of hydrogen.

There is a variety of onium salts of organic acids-oxidizers. Among those, there are many onium salts of primary nitramines. These compounds are readily available; as a rule, their synthesis is not complicated.

Table 6 Energy potential of formulations with octanitrocubane

\begin{tabular}{lcccccccccc}
\hline \multirow{2}{*}{ Binder } & $\begin{array}{c}\text { Binder, } \\
\%(\text { wt.) }\end{array}$ & $\begin{array}{c}\text { Boron, } \\
\%\end{array}$ & $\begin{array}{c}\mathrm{Al}, \\
\%\end{array}$ & $\begin{array}{c}I_{\mathrm{sp}}, \\
\mathrm{s}\end{array}$ & $\begin{array}{c}\rho, \\
\mathrm{g} / \mathrm{cm}^{3}\end{array}$ & $\begin{array}{c}T_{c}, \\
\mathrm{~K}\end{array}$ & $\begin{array}{c}T_{a}, \\
\mathrm{~K}\end{array}$ & $\begin{array}{c}E_{1} \\
\mathrm{~g}, \mathrm{~cm}^{3}, \mathrm{~s}\end{array}$ & $E_{3}$ \\
\hline $\mathrm{HB}$ & 8 & 0 & 0 & 262.5 & 1.87 & 3730 & 2360 & 382.2 & 337.2 & 297.5 \\
$\mathrm{HB}$ & 10 & 0 & 0 & 260.8 & 1.83 & 3650 & 2090 & 374.8 & 332.1 & 294.3 \\
$\mathrm{HB}$ & 10 & 0 & 6 & 263.4 & 1.88 & 3770 & 2330 & 384.7 & 339.1 & 298.8 \\
PMVT & 12 & 10 & 0 & 262.9 & 1.96 & 4100 & 2800 & 393.7 & 344.1 & 300.8 \\
\hline
\end{tabular}


Table 7 Energy potential of formulations based on salts of methylenedinitramine

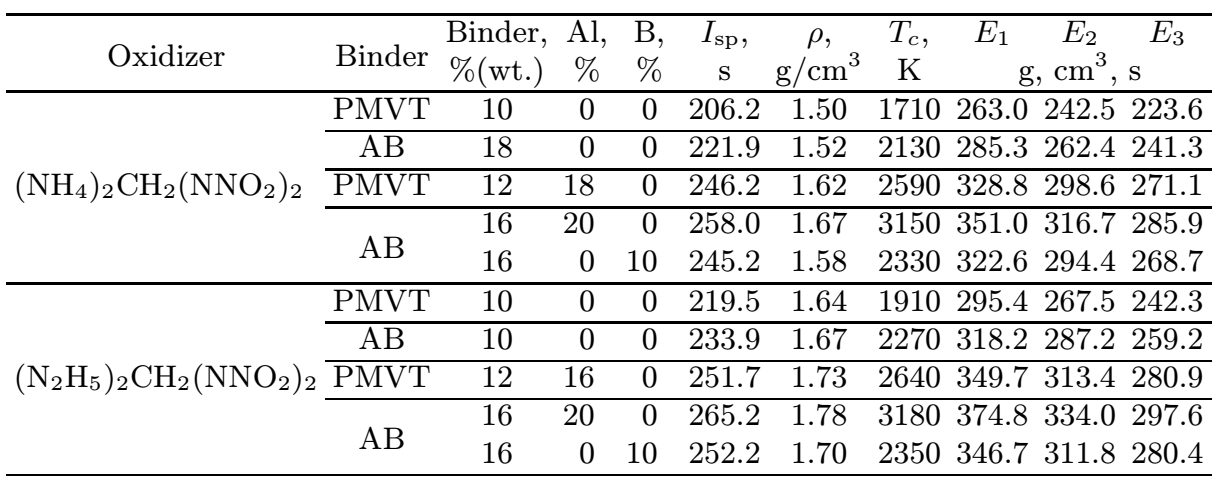

The energy potential of the formulations based on ammonium and hydrazonium salts of methylenediniramine are presented in Table 7 . One can see that high properties can be attained using hydrazonium salt; however, stability of this salt is insufficient for its use as a component in solid composite propellants.

Additionally to that, almost all hydrazonium salts manifest remarkably strong impact and friction sensivity, whereas hydroxylammonium salts are too hygroscopic, have poor compatibility with other components of solid propellants, and often insufficiently stable. The stability of hydrazonium and hydroxylammonium salts depends on the strength of the acid and its activity as an oxidizer. Thermal stability of the salts grows with increasing the acid strength and reducing its activity as an oxidizer, as thermal decomposition of the onium salts proceeds via proton transfer and the formation of the free base in equilibrium concentration. The base either reacts with free acid or decomposes itself. Hydroxylammonium perchlorate (HAP), the salt of a very strong perchloric acid, manifests insufficient stability to be promptly used as a component for solid composite propellant.

Using special methods, by achieving a shift in the equilibrium to formation of a little excess of free acid, one can substantially increase its thermal stability [5]. In the series $\mathrm{NH}_{4}^{+} \mathrm{X}^{-}, \mathrm{N}_{2} \mathrm{H}_{5}^{+} \mathrm{X}^{-}$, and $\mathrm{NH}_{3} \mathrm{OH}^{+} \mathrm{X}^{-}$, ammonium salts are the most stable, hydrazonium are less stable, and hydroxylammonium salts are the least stable. The first reason is that alkalinity of onium base decreases substantially from ammonium to hydroxylammonium. The second, the reducing activity of the base increases in the same series while thermal stability of the base as a compound drops.

Table 8 shows the formulations with ammonium and hydrazonium salts of nitroform. The higher energy parameters of hydrazonium salts are obvious. 
Table 8 Energy potential of formulations with nitroform salts

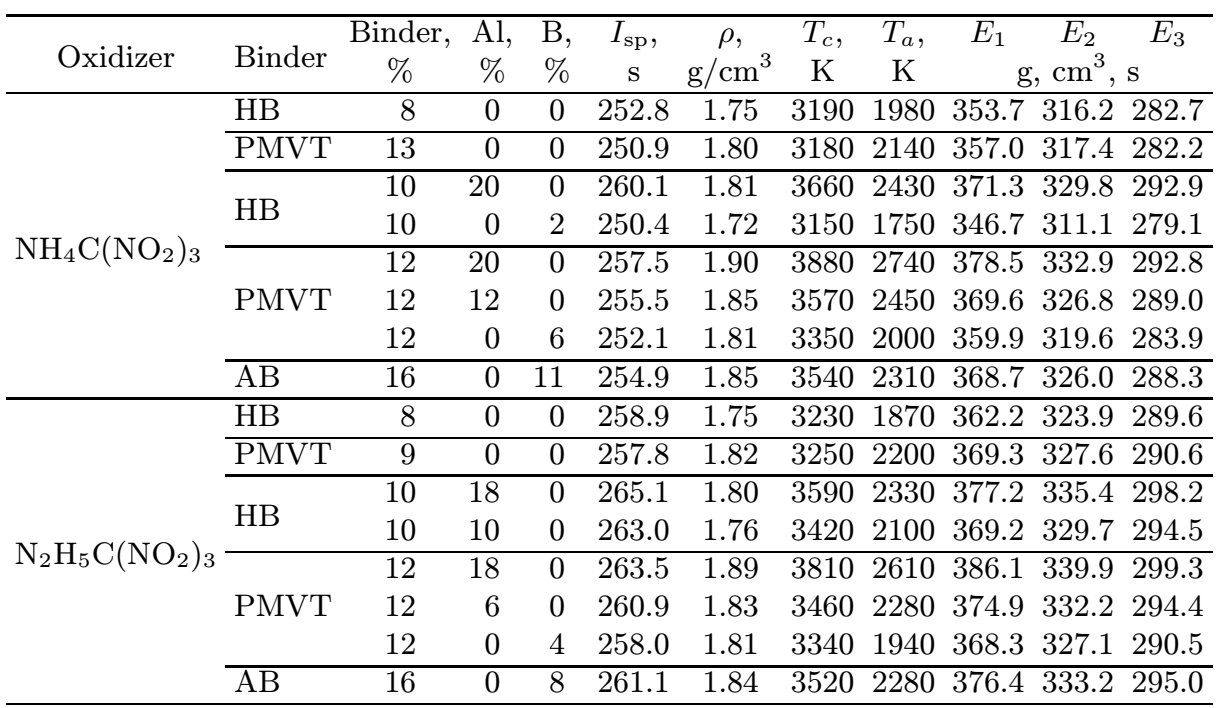

Recently, a number of papers have been devoted to studies of possible application of high-enthalpy CHNO oxidizers, e.g., from the series of substituted five-member N-heterocycles (pyrrole $(I) \rightarrow$ pyrazole $(I I) \rightarrow 1,2,3$-triazole $(I I I)$ $\rightarrow$ tetrazole $(I V)[6,7]$.<smiles>[X]c1c([X])c([X])n([Tl])c1[X]</smiles><smiles>[X]c1nn([Tl])c([X])c1[X]</smiles><smiles>[X]c1nn([Tl])nc1[X]</smiles><smiles>[X]c1nnn([Tl])n1</smiles>

where $X, Y$ are $\mathrm{NO}_{2}, \mathrm{C}\left(\mathrm{NO}_{2}\right)_{3}$, or other oxidizing groups. These compounds may be interesting as components of solid composite propellants only with a large number of constituents incorporating oxidizing groups. In the series from pyrrole to tetrazole, the $\Delta H_{f}^{0}$ value of such oxidizers increases and so does oxygen balance. The derivatives of furozanes, furoxanes, and other five-, six-member Nheterocycles can also make potential oxidizers (Table 9). 
Table 9 Energy potential of formulations based on high-enthalpy organic oxidizers

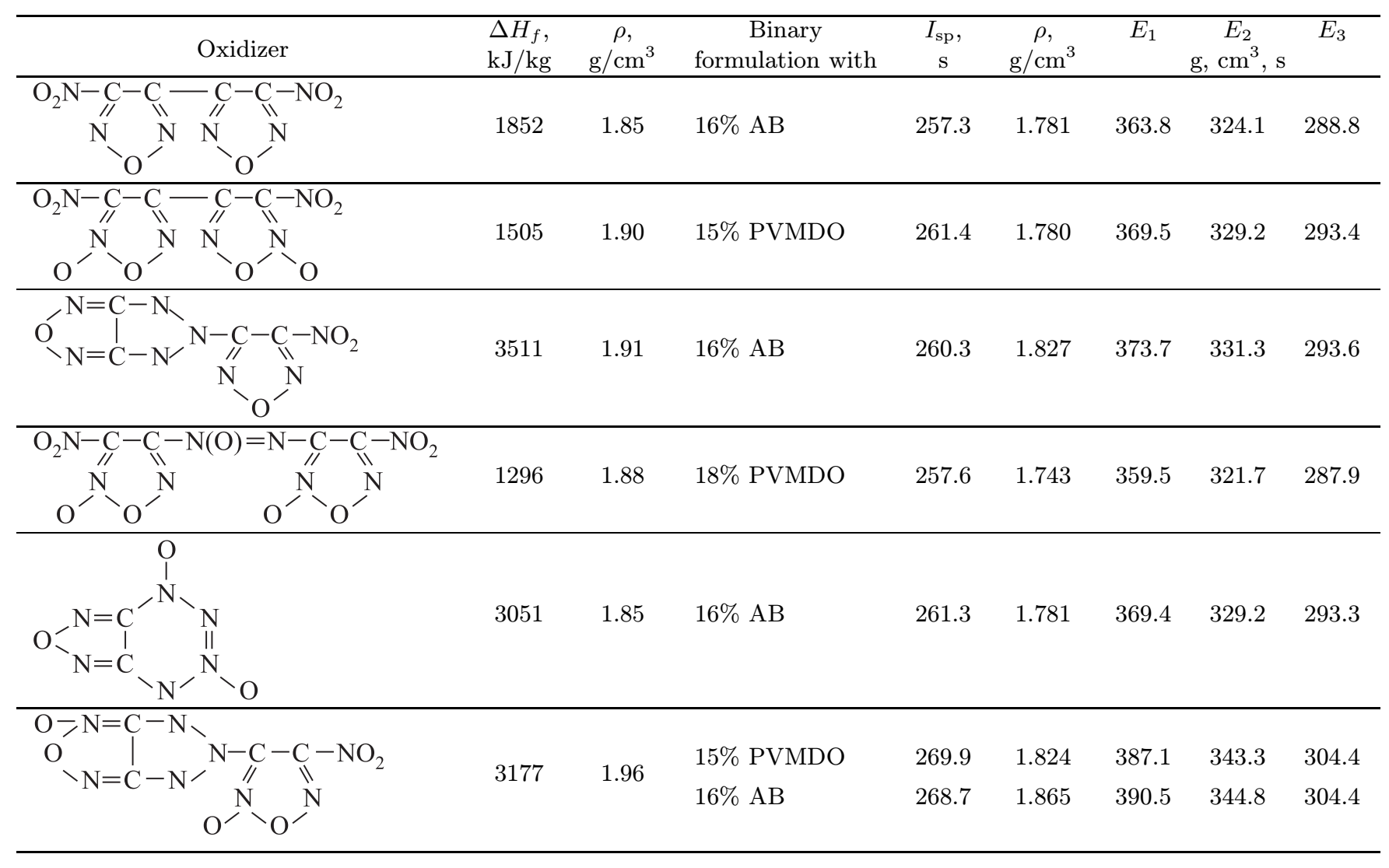




\section{A POSSIBILITY TO SUBSTANTIALLY ENHANCE ENERGY POTENTIAL OF SOLID COMPOSITE PROPELLANTS THROUGH INTRODUCTION OF ALUMINUM HYDRIDE}

A possibility to use $\mathrm{AH}\left(\mathrm{AlH}_{3},-12 \mathrm{~kJ} / \mathrm{mol}, \rho=1.48 \mathrm{~g} / \mathrm{cm}^{3}\right)$ as an energetic component instead of aluminum was studied from early 1960s. Indeed, AH plays not only the role of energetic component, but also gas-generating one; this provides a possibility to increase $I_{\mathrm{sp}}$ dramatically. The efficiency of $\mathrm{AH}$, however, is materialized only when an AB is used. Therefore, the extensive search aimed at synthesis and manufacturing of binders incorporating large fraction of nitroether-, nitro-, or nitramine groups was performed in parallel with the search of optimal ways for $\mathrm{AH}$ synthesis and improvement of its operational properties. The initial AH-containing compositions were really created and manufactured in small amounts of AP as oxidizer; further, several years later, the ones with ADN were created as well. Table 10 shows the efficiency of AH on the example of formulations with ADN. Note that the binder volume fraction is also presented in the table. Since AH particles constitute a very fine fraction, there must be at least $25 \%$ by volume of binder for $25 \%$ (wt.) of $\mathrm{AH}$ in the formulation (while for aluminum-containing formulations, the minimum volume fraction of binder is $18 \%-19 \%$ ). For a lower content of binder, it is virtually impossible to prepare a propellant with satisfactory mechanical and rheological properties.

Table 11 presents the data for $\mathrm{AH}$-containing formulations with different oxidizers and $\mathrm{AB}$. It shows that the use of $\mathrm{AH}$ allows one to overcome to a certain extent the disadvantages of an oxidizer; the formulations based on AN do not lose much to those with ADN, HAP, or HNF. Presently, the major factor limiting wide use of $\mathrm{AH}$ is its high cost.

Table 10 Energy parameters of formulations $25 \%$ AH + binder + ADN depending on binder type and content

\begin{tabular}{|c|c|c|c|c|c|c|c|}
\hline \multirow[b]{2}{*}{ Binder } & \multicolumn{2}{|c|}{ Binder content } & \multirow{2}{*}{$\begin{array}{c}I_{\mathrm{sp}} \\
\mathrm{s}\end{array}$} & \multirow{2}{*}{$\begin{array}{c}\rho, \\
\mathrm{g} / \mathrm{cm}^{3}\end{array}$} & \multirow{2}{*}{$\begin{array}{c}T_{c} \\
\mathrm{~K}\end{array}$} & $E_{2}$ & \multirow{2}{*}{$\begin{array}{c}E_{3} \\
, \mathrm{~s}\end{array}$} \\
\hline & $\%$ (wt.) & $\%$ (vol.) & & & & $\mathrm{g}, \mathrm{cm}^{3}, \mathrm{~s}$ & \\
\hline \multirow{3}{*}{ HB } & 13 & 21.9 & 270.2 & 1.532 & 2788 & 320.5 & 294.3 \\
\hline & 16 & 26.3 & 263.7 & 1.494 & 2631 & 309.6 & 285.7 \\
\hline & 18 & 28.6 & 260.0 & 1.470 & 2527 & 303.3 & 280.8 \\
\hline \multirow{3}{*}{ PVMDO } & 20 & 25.5 & 279.2 & 1.603 & 3379 & 337.2 & 306.8 \\
\hline & 25 & 30.1 & 278.8 & 1.576 & 3258 & 334.4 & 305.4 \\
\hline & 29 & 34.4 & 276.0 & 1.560 & 3100 & 329.7 & 301.7 \\
\hline \multirow[b]{2}{*}{$\mathrm{AB}$} & 25 & 27.2 & 277.5 & 1.621 & 3542 & 336.6 & 305.6 \\
\hline & 30 & 32.6 & 277.2 & 1.618 & 3525 & 336.0 & 305.2 \\
\hline
\end{tabular}


Table 11 Energy parameters of formulations with AH, AB, and different oxidizers

\begin{tabular}{|c|c|c|c|c|c|c|c|}
\hline Oxidizer & $\begin{array}{c}\mathrm{AH}, \\
\%\end{array}$ & $\begin{array}{c}\text { Binder AB, } \\
\% \text { (wt.) }\end{array}$ & $\begin{array}{c}I_{\mathrm{sp}} \\
\mathrm{s}\end{array}$ & $\begin{array}{c}\rho, \\
\mathrm{g} / \mathrm{cm}^{3} \\
\end{array}$ & $\begin{array}{c}T_{c}, \\
\mathrm{~K} \\
\end{array}$ & $\begin{array}{l}E_{2} \\
\mathrm{~g}, \mathrm{~cm}^{3}\end{array}$ & $\begin{array}{l}E_{3} \\
3, \mathrm{~s} \\
\end{array}$ \\
\hline \multirow{2}{*}{ AP } & \multirow{2}{*}{25} & 25 & 270.1 & 1.685 & 3587 & 332.8 & 299.8 \\
\hline & & 30 & 270.8 & 1.663 & 3546 & 331.9 & 299.8 \\
\hline \multirow{2}{*}{ HAP } & \multirow[b]{2}{*}{25} & 25 & 277.5 & 1.634 & 3564 & 337.7 & 306.1 \\
\hline & & 30 & 274.1 & 1.700 & 3674 & 338.9 & 304.8 \\
\hline \multirow[b]{2}{*}{$\mathrm{ADN}$} & \multirow[b]{2}{*}{25} & 25 & 277.5 & 1.621 & 3542 & 336.6 & 305.6 \\
\hline & & 30 & 277.2 & 1.618 & 3525 & 336.0 & 305.2 \\
\hline \multirow[b]{2}{*}{$\mathrm{AN}$} & \multirow[b]{2}{*}{25} & 25 & 267.4 & 1.595 & 3208 & 322.3 & 293.6 \\
\hline & & 30 & 268.0 & 1.583 & 3202 & 322.1 & 293.8 \\
\hline \multirow{2}{*}{$\mathrm{HNF}$} & \multirow[b]{2}{*}{25} & 25 & 279.8 & 1.666 & 3584 & 343.2 & $\overline{309.9}$ \\
\hline & & 30 & 279.2 & 1.646 & 3537 & 340.8 & 308.5 \\
\hline \multirow{2}{*}{$\left(\mathrm{N}_{2} \mathrm{H}_{5}\right)_{2} \mathrm{CH}_{2}\left(\mathrm{NNO}_{2}\right)_{2}$} & \multirow[b]{2}{*}{21} & 25 & 271.9 & 1.588 & 2873 & 327.2 & 298.2 \\
\hline & & 30 & 271.3 & 1.574 & 2776 & 325.3 & 297.1 \\
\hline
\end{tabular}

\section{THE WAYS TO SECURE NECESSARY COMBUSTION PROPERTIES OF SOLID COMPOSITE PROPELLANTS}

A solid propellant can be used in practice only when a proper combustion law is secured, i.e., the combustion rate must equal a required value for a prescribed pressure within a chamber, the exponent $\nu$ in the formula relating the combustion rate to pressure $\left(W=A P^{\nu}\right)$ must belong to a certain range (in the majority of cases, $0.3<\nu<0.4$ is optimal).

The combustion mechanism of solid composite propellants cannot be satisfactorily formulated and described without a preliminary description of the combustion mechanism of oxidizers. The latter mechanism is primarily governed by exothermic decomposition and sublimation (evaporation) of the substance. This provides a controlling and stabilizing action on the formulation combustion as it enters the overall heat balance at the combustion surface. The combustion rate can be varied not only via oxidizer decomposition accelerated with a catalyst but also by reducing oxidizer volatility (e.g., due to introduction of alkaline metal salts).

The kinetics plays an important role in the combustion mechanism of solid composite propellant; important is the ratio of oxidizer decomposition rate to the rate of fuel oxidation at the initial stages of combustion. For a sufficiently stable oxidizer (e.g., AP), a nonvolatile fuel can get partially oxidized in condensed phase and thus contribute to the heat balance; this has a stabilizing effect on combustion and enhances the combustion rate, compared to pure oxidizer. 
In the case of readily decomposing oxidizer (e.g., ADN) and a relatively thermally stable fuel, the conversion rates for both components can have such a ratio that, owing to heat consumption for heating and gasification, the fuel oxidation does not occur in the condensed phase and, as heat flux from the gaseous phase is insufficient, the combustion rate of the formulation becomes lower than that for a neat oxidizer.

The same mechanism accounts for the anomalous dependence of the combustion rate on the particles size for this type of oxidizer, the combustion rate grows with increasing oxidizer particles. Therefore, the use of sufficiently thermally stable components bearing highly reactive functional groups, the latter oxidizing fast and with high heat effect, provides efficient way to enhance the combustion rate.

At all stages of propellant combustion, the heat and mass transfer between the components affect both the combustion rate and its dependence on external conditions and intrinsic features of the formulation (particles size, reactivity). The interplay of these factors and reaction kinetics determines combustion proceeding in kinetic, diffusion-kinetic, heat exchange, or autonomous regime. The ways to control these regimes include variation of components dispersion and also higher homogeneity of propellant by combining in one phase or one component the features of both oxidizer and fuel (e.g., guanidinium nitrate or guanidinium nitramide) or oxidizer, fuel, and catalyst (e.g., ferricinium salts).

These ways also include surface covering of oxidizer particles with the films, which have a catalytic, inhibiting, or highly energetic effect. The combustion rate depends on chemical reactions of oxidation and decomposition proceeding in both condensed and gaseous phases. The nature of intermediate products of combustion (decomposition) is also important. For example, some chlorine oxides, which are the intermediates in combustion of AP, are active oxidizers, whereas the decomposition products of AN and certain organic oxidizers are much less chemically reactive.

The rate of condensed-phase reactions governs the combustion rate for formulations based on low-volatile compounds (primarily, inorganic ion salts: AP, $\mathrm{ADN})$. This rate, in its turn, depends on the temperature of the surface, which is controlled by the ratio of evaporation and decomposition rates [8]. For the above mentioned compounds, this ratio is of such a value that $\nu$ in $W=A P^{\nu}$ is within 0.3 to 0.5 .

For volatile organic compounds, the condensed phase evaporates completely at relatively low temperature, where thermal decomposition has not occurred yet and gas phase reaction at the maximum combustion temperature controls the process (combustion mechanism described by Belyaev-Zel'dovich theory). In this case, the combustion rate strongly depends on pressure $(\nu \approx 1)$. The case of not very stable and relatively volatile organic compounds like HMX, RDX, etc. is an intermediate one. Here, heat transfer from gaseous phase becomes noticeable. For such systems, $\nu \approx 0.5-0.7$. Therefore, for the formulations with high HMX 
content, one must introduce some small concentrations of AP (5\%-10\%) in order to bring $\nu$ down.

\section{CONCLUDING REMARKS}

The combustion products of the formulations containing beryllium and/or AP are most harmful for the environment.

The environmental impact of propellants based on AP can be substantially reduced through the use of the mixed oxidizer, equimolar mixture of AP with sodium nitrate. This, however, brings down the energy potential of the propellant.

The major pollutant in the combustion products of chlorine-free formulations is carbon monoxide and its formation is unavoidable. Nevertheless, fast dilution of gaseous products in atmosphere and partial oxidation with air rapidly bring $\mathrm{CO}$ concentration to admissible values.

The energy potential of propellant components can be materialized in optimal formulations, e.g., with a choice of a proper binder for a particular oxidizer, presence or absence of metal or hydride.

When developing new propellant formulations, from the very start, one should consider for what class of rockets this propellant is made for; the formulation should be optimized for particular case with the ballistic efficiency depending on both specific impulse and density.

Use of aluminum hydride provides the way to substantially enhance energy potential of propellants; it should be employed with ABs enriched in oxygen.

The development of new propellant formulations requires consideration, in addition to high energy potential of a formulation, of a number of other properties (appropriate combustion law, sufficient thermal stability, compatibility, low sensitivity to friction and shock, etc.).

\section{REFERENCES}

1. Lempert, D. B., G. N. Nechiporenko, G.P. Dolganova, and L. N. Stesik. 1997. Energetics of low pollution solid propellants. Chem. Phys. Rep. 16(9):1629-41.

2. Lukyanov, O. A., and V.A. Tartakovskii. 1997. Chemistry of dinitramide and its salts. Rus. Chem. J. 41(2):5-13.

3. Nechiporenko, G. N., and D. B. Lempert. 1998. An analysis of energy potentialities of composite solid propellants containing beryllium or beryllium hydride as an energetic component. Chem. Phys. Rep. 17:1927-47.

4. Nielsen, A. T., M. L. Chan, K. J. Kraeutle, et al. 1989. Polynitropolyaza-caged explosives. No. 7, Naval Weapon Center. China Lake, CA. NWC TP 7020. 
5. Lempert, D. B., G.P. Dolganova, and G. N. Nechiporenko. 1998. Thermal decomposition of hydroxylammonia perchlorate at low degradation level. Rus. J. Appl. Chem. 3:365-70.

6. Lempert, D. B., G. N. Nechiporenko, and S. I. Soglasnova. 2004. Dependence of specific impulse of solid composite propellants containing oxidizers based on $\mathrm{C}, \mathrm{N}$, and O-atoms on the formation enthalpy and element content of the oxidizer. Rus. J. Chem. Phys. 23(5):75-81.

7. Nechiporenko, G. N., D. B. Lempert, and S. I. Soglasnova. 2005. Dependence of specific impulse of solid composite propellants containing nitroderivatives of fivemember $\mathrm{N}$-heterocycles on the amount of $\mathrm{N}$-atoms in the cycle and on the binder type. Rus. J. Chem. Phys. 24(3):74-80.

8. Manelis, G. B., G. M. Nazin, Yu. I. Rubtsov, and V. A. Strunin. 2003. Thermal decomposition and combustion of explosives and propellants. London-New York: Taylor and Francis Group. 